\title{
KARAKTERISTIK ENKAPSULAT PEWARNA FUNGSIONAL DARI EKSTRAK SELADA LAUT (Ulva lactuca L) PADA PERLAKUAN PERBANDINGAN GELATIN DAN MALTODEKSTRIN
}

\author{
Characteristics of The Encapsulates Functional Dyes of Sea Lettuce Extract (Ulva lactuca L)
} on The Treatment of Gelatin and Maltodextrin Comparison

\author{
I Wayan Eko Fridayana, Luh Putu Wrasiati", G.P. Ganda Putra \\ PS Teknologi Industri Pertanian, Fakultas Teknologi Pertanian, Universitas Udayana, Kampus Bukit \\ Jimbaran, Badung, Kode pos : 80361; Telp/Fax : (0361) 701801.
}

Diterima 08 Oktober 2018 / Disetujui 19 Oktober 2018

\begin{abstract}
Sea lettuce can be used as a functional green dye because it contains chlorophyll. Chlorophyll compounds as green coloring are obtained by extraction and stored in the form of encapsulation powder. This study has two purpose, there are to knowing the effect of the gelatin-maltodextrin encapsulant ratio on the encapsulates charagcteristics of sea lettuce functional coloring extract and determine the encapsulates comparison treatment of the best gelatin-maltodextrins in producing the characteritic encapsulates extract of sea lettuce functional coloring. Experiments in this study using a Randomized Single Factor Group with treatment ratio of gelatin and maltodextrin consisting of 9 levels, namely (1:0), (1:1), (1:1,5), (1:2), (1:2,5), (1:3), (1:3,5), (1:4), and (0:1). The results showed that the ratio of gelatin-maltodextrin was highly significant $(P<0.01)$ on yield, total chlorophyll content, solubility, brightness level, significantly $(P<0.05)$ on the level of redness $\left(a^{*}\right)$, yellowish level $\left(b^{*}\right)$ and no effect $(P>0.05)$ on water content. The treatment of gelatin-maltodextrin 1:2,5 ratio is the best treatment to produce encapsulate sea lettuce extract with yield of $10.38 \%$, water content of $8.61 \%$, total chlorophyll content of 20.59 ppm, solubility of $0.80 \%$, brightness level $\left(L^{*}\right) 45.21$, redness level $\left(a^{*}\right)$ 1.68 and yellowish level $\left(b^{*}\right) 13.88$.
\end{abstract}

Keywords :Sea lettuce extract, gelatin, maltodextrin, encapsulation.

\begin{abstract}
ABSTRAK
Selada laut dapat dijadikan sebagai pewarna hijau fungsional karena mengandung klorofil. Senyawa klorofil sebagai pewarna hijau didapatkan dengan cara ekstraksi dan disimpan dalam bentuk bubuk enkapsulasi. Tujuan penelitian ini ada 2 yaitu mengetahui pengaruh perbandingan enkapsulan gelatinmaltodekstrin terhadap karakteristik enkapsulat ekstrak pewarna fungsional selada laut dan menentukan perlakuan perbandingan enkapsulan dari gelatin-maltodekstrin terbaik dalam menghasilkan enkapsulat karakteritik ekstrak pewarna fungsional selada laut. Percobaan dalam penelitian ini menggunakan Rancangan Acak Kelompok faktor tunggal dengan perlakuan perbandingan gelatin dan maltodekstrin yang terdiri dari 9 taraf yaitu (1:0), (1:1), (1:1,5), (1:2), (1:2,5), (1:3), (1:3,5), (1:4), dan (0:1). Hasil penelitian menunjukkan bahwa perbandingan gelatin-maltodekstrin berpengaruh sangat nyata $(P<0,01)$ terhadap rendemen, kadar klorofil total, kelarutan, tingkat kecerahan, berpengaruh nyata $(\mathrm{P}<0,05)$
\end{abstract}

\footnotetext{
*Korespondensi Penulis:

Email:wrasiati@unud.ac.id
} 
terhadap tingkat kemerahan $\left(\mathrm{a}^{*}\right)$, tingkat kekuningan $\left(\mathrm{b}^{*}\right)$ dan tidak berpengaruh $(\mathrm{P}>0,05)$ terhadap kadar air. Perlakuan perbandingan gelatin-maltodekstrin 1:2,5 merupakan perlakuan terbaik untuk menghasilkan enkapsulat ekstrak selada laut dengan rendemen $10,38 \%$, kadar air 8,61\%, kadar total klorofil 20,59 ppm, kelarutan 0,80\%, tingkat kecerahan ( $\left.\mathrm{L}^{*}\right)$ 45,21, tingkat kemerahan (a*) 1,68 dan tingkat kekuningan $\left(b^{*}\right) 13,88$.

Kata kunci : ekstrak selada laut, gelatin, maltodekstrin, enkapsulasi

\section{PENDAHULUAN}

Selada laut (Ulva lactuca L.) adalah makroalga laut yang banyak digunakan sebagai bahan pangan oleh masyarakat Indonesia (Julyasih et al., 2009). Selada laut tumbuh diberbagai habitat, di bebatuan, terutama pada fragmen karang mati di pesisir Pantai Bali terutama di Pantai Serangan, tumbuh secara liar dan tidak dimanfaatkan secara ekonomis oleh masyarakat sekitar. Secara umum, bubuk selada laut jenis Ulva lactuca L mengandung air 18,7\% dan klorofil 13,15\% (Xiao-ling et al., 2003). Kandungan klorofil pada ekstrak selada laut yang dihasilkan dipengaruhi oleh beberapa faktor diantaranya konsentrasi pelarut dan suhu maserasi. Kandungan klorofil selada laut yang cukup tinggi menjadikan selada laut berpotensi sebagai pewarna hijau yang fungsional.

Sediaan ekstrak pewarna dalam bentuk cair kurang praktis karena kesulitan pada saat pengemasan, penyimpanan dan pendistribusiannya sehingga digunakan proses enkapsulasi untuk mengubah sediaan cair menjadi bubuk atau padat. Enkapsulasi merupakan teknik penjeratan bahan inti dan bahan penyalut tertentu. Enkapsulasi bertujuan untuk melindungi komponen bahan yang sensitif dan mengurangi degradasi senyawa aktif dalam bahan (Palupi et al., 2014). Teknik enkapsulasi salah satunya dengan teknik pengeringan lapis tipis dilakukan oleh Silalahi et al. (2014).

Proses enkapsulasi memerlukan bahan inti dan bahan penyalut atau enkapsulan. Bahan inti dapat berupa emulsi atau gas. Pada penelitian ini bahan enkapsulan yang digunakan adalah maltodekstrin dan gelatin.
Maltodekstrin digunakan karena mempunyai sifat yang mudah larut dalam air. Maltodekstrin lemah dalam membentuk emulsi sehingga perlu kombinasi dengan enkapsulan lain atau emulsifier dalam penelitian ini kombinasi yang digunakan adalah maltodekstrin dan gelatin. Pada penelitian ini, formulasi gelatin dan maltodeksrin digunakan untuk proses enkapsulasi ekstrak selada laut sebagai pewarna fungsional. Penelitian ini bertujuan untuk mengetahui pengaruh perbandingan enkapsulan gelatin-maltodekstrin terhadap karakteristik enkapsulat ektrak pewarna fungsional selada laut dan menentukan perlakuan perbandingan enkapsulan dari gelatin-maltodekstrin terbaik dalam menghasilkan enkapsulat ekstrak pewarna fungsional selada laut.

\section{METODE PENELITIAN}

\section{Bahan dan Alat}

Bahan yang digunakan dalam penelitian ini terdiri dari selada laut jenis Ulva lactuca L yang diperoleh dari Pantai Serangan Bali ( $8^{\circ} 43^{\prime} 24.7^{\prime \prime} \mathrm{S}$ dan $\left.115^{\circ} 13^{\prime} 50.9^{\prime \prime} \mathrm{E}\right)$, etanol teknis $96 \%$ (Bratachem), akuades, aseton pa (Merck), bahan enkapsulan maltodekstrin (Brataco) dan gelatin (Brataco).

Peralatan yang digunakan dalam penelitian ini terdiri rotary vacum evaporator (IKA* RV 10 basic), oven pengering (BLUE $M)$, vortex (Barnsteadl Thermolyne), ayakan 60 mesh, kain saring, kertas Whatman No 1, homogenizer (BRANSON), blender (HR 2116), cawan petri, kertas label, pisau, gelas beker, timbangan analitik (SHIMADZU AY220), gelas ukur, aluminium foil, labu erlenmeyer. 
Pelaksanaan Penelitian

\section{Pembuatan ekstrak selada laut (Dewi et al.,} 2016)

Selada laut segar dipotong-potong dengan ukuran $\pm 2 \mathrm{~cm} \times 2 \mathrm{~cm}$ dengan tujuan untuk mempermudah pengeringan dan penghancuran. Potongan selada laut dioven pada suhu $50^{\circ} \mathrm{C} \pm 5^{\circ} \mathrm{C}$ selama 24 jam sampai selada laut mudah dihancurkan. Selada laut kering dihancurkan dengan blender sampai halus. Kemudian diayak menggunakan ayakan 60 mesh. Pembuatan ekstrak selada laut dilakukan secara maserasi, yaitu dengan menimbang $40 \mathrm{~g}$ bubuk selada laut dan dimasukkan kedalam labu erlenmeyer, lalu ditambahkan pelarut etanol $90 \%$ masingmasing sebanyak $240 \mathrm{~mL}$ sehingga didapatkan perbandingan bubuk dengan etanol adalah 1:6 (Yuliani et al., 2007). Selanjutnya dimaserasi selama 48 jam pada suhu $45 \pm 2^{\circ} \mathrm{C}$ dan dilakukan pengadukan setiap 6 jam selama 5 menit. Larutan kemudian disaring dengan menggunakan kain saring biasa untuk menyaring ampas yang berukuran besar, selanjutnya kertas Whatman No. 1 untuk menyaring ampas yang berukuran kecil. Filtrat yang dihasilkan diuapkan untuk menghilangkan pelarut menggunakan rotary evaporator dengan suhu $50^{\circ} \mathrm{C}$ dengan tekanan $100 \mathrm{mBar}$ sehingga dihasilkan ekstrak kental. Penghentian proses evaporasi ditentukan dari tidak adanya pelarut yang menetes.

\section{Enkapsulasi ekstrak selada laut (Yogaswara et al., 2017 yang telah dimodifikasi)}

Pembuatan produk enkapsulasi ekstrak selada laut menggunakan metode pengeringan lapis tipis (thin layer drying) mengikuti prosedur penelitian Yogaswara et al. (2017) dengan modifikasi. Pembuatan larutan enkapsulan sebanyak $50 \mathrm{~mL}$ dilakukan dengan menimbang gelatin dan maltodekstrin sebanyak $10 \%$ dari volume larutan (5 gram) dengan komposisi sesuai perlakuan kemudian ditambah akuades sampai $50 \mathrm{~mL}$. Kemudian dimasukan ekstrak selada laut sebanyak $1 \%$ dari volume larutan enkapsulan dan langsung dihomogenasi dengan homogenezier selama 30 menit. Larutan enkapsulasi dituang ke dalam cawan petri dengan ketebalan $3 \mathrm{~mm}$ dan dikeringkan dengan oven suhu $50 \pm 5^{\circ} \mathrm{C}$ sampai mudah dilepaskan dari cawan petri (sekitar 13 jam). Kemudian enkapsulat dihancurkan dan diayak menggunakan ayakan 40 mesh.

\section{Variabel yang Diamati}

Variabel yang diamati dalam penelitian ini adalah rendemen (Sudarmadji et al., 1989), kadar air (Sudarmadji et al., 1997), klorofil total (Nollet, 2004), kelarutan (AOAC, 1984), intensitas warna (Caliskan, 2016).

\section{HASIL DAN PEMBAHASAN}

\section{Rendemen}

Hasil analisis keragaman menunjukkan bahwa perlakuan perbandingan gelatin dan maltodekstrin berpengaruh sangat nyata $(\mathrm{P}<0,01)$ terhadap rendemen enkapsulat pewarna fungsional ekstrak selada laut.

Tabel 1 menunjukkan bahwa hasil rendemen perlakuan GM7 sebesar 11,22\% dan tidak berbeda dengan perlakuan GM8 sebesar $11,13 \%$ merupakan rendemen tertinggi. Rendemen yang tinggi disebabkan oleh jumlah maltodekstrin yang lebih banyak (1:4) akan lebih mampu melakukan interaksi terhadap fraksi yang dikapsulkan. Semakin banyak jumlah maltodekstrin maka semakin besar total padatan yang diperoleh (Endang dan Prasetyastuti, 2010). Hasil yang diperoleh sesui dengan pernyataan Hustiany (2006), semakin besar jumlah maltodekstrin pada enkapsulasi, semakin besar pula rendemen produk enkapsulasi. 
Tabel 1. Nilai rata-rata rendemen enkapsulat pewarna fungsional ekstrak selada laut $(\%)$

\section{Perbandingan Gelatin (G) dan Maltodekstrin (M) Rendemen (\%)}

\begin{tabular}{lc}
\hline GM0 $(1: 0)$ & $8,79 \pm 0,05^{\mathrm{e}}$ \\
GM1 $(1: 1)$ & $8,81 \pm 0,04^{\mathrm{de}}$ \\
GM2 $(1: 1,5)$ & $9,04 \pm 0,03^{\mathrm{d}}$ \\
GM3 $(1: 2)$ & $9,73 \pm 0,06^{\mathrm{c}}$ \\
GM4 $(1: 2,5)$ & $10,38 \pm 0,08^{\mathrm{b}}$ \\
GM5 $(1: 3)$ & $10,40 \pm 0,10^{\mathrm{b}}$ \\
GM6 $(1: 3,5)$ & $10,60 \pm 0,04^{\mathrm{b}}$ \\
GM7 $(1: 4)$ & $11,22 \pm 0,01^{\mathrm{a}}$ \\
GM8 $(0: 1)$ & $11,13 \pm 0,08^{\mathrm{a}}$ \\
\hline
\end{tabular}

Keterangan : Huruf yang berbeda di belakang nilai rata-rata menunjukkan perbedaan sangat nyata $(\mathrm{P}<0,01)$.

\section{Kadar Air (\%)}

Hasil analisis keragaman menunjukkan bahwa perlakuan perbandingan gelatin dan maltodekstrin berpengaruh tidak nyata $(\mathrm{P}>0,05)$ terhadap kadar air enkapsulat pewarna fungsional ekstrak selada laut.

Tabel 2 menunjukkan kadar air enkapsulat pewarna fungsional ekstrak selada laut, akan tetapi terdapat kecenderungan penurunan kadar air pada enkapsulat pewarna fungsional selada laut tidak berbeda antar perlakuanakan tetapi terdapat kecendrungan penurunan kadar air pada enkapsulat pewarna fungsional selada laut dengan meningkatnya konsentrasi maltodekstrin. Semakin tinggi penambahan maltodekstrin maka cenderung semakin rendah kadar air enkapsulat pewarna fungsional ekstra selada laut karena konsentrasi maltodekstrin cenderung akan menyebabkan penambahan total padatan yang mengakibatkan penurunan kadar air. Penambahan maltodekstrin dengan jumlah yang banyak dapat menurunkan kadar air dari produk (Hui, 2002).

Tabel 2. Nilai rata-rata kadar air enkapsulat pewarna fungsional ekstrak selada laut $(\%)$.

\section{Perbandingan Gelatin (G) dan Maltodekstrin (M) Kadar air (\%)}

\begin{tabular}{ll}
\hline GM0 $(1: 0)$ & $8,69 \pm 0,68^{\mathrm{a}}$ \\
GM1 $(1: 1)$ & $8,68 \pm 1,16^{\mathrm{a}}$ \\
GM2 $(1: 1,5)$ & $8,67 \pm 1,24^{\mathrm{a}}$ \\
GM3 $(1: 2)$ & $8,63 \pm 0,09^{\mathrm{a}}$ \\
GM4 $(1: 2,5)$ & $8,61 \pm 0,36^{\mathrm{a}}$ \\
GM5 $(1: 3)$ & $8,61 \pm 0,50^{\mathrm{a}}$ \\
GM6 $(1: 3,5)$ & $8,59 \pm 0,65^{\mathrm{a}}$ \\
GM7 $(1: 4)$ & $8,59 \pm 0,49^{\mathrm{a}}$ \\
GM8 $(0: 1)$ & $8,58 \pm 0,24 \mathrm{a}$ \\
\hline
\end{tabular}

Keterangan : Huruf sama yang berbeda di belakang nilai rata-rata menunjukkan tidak berpengaruh $(\mathrm{P}>0,05)$. 


\section{Kadar Total Klorofil}

Hasil analisis keragaman menunjukkan bahwa perlakuan perbandingan gelatin dan maltodekstrin berpengaruh sangat nyata $(\mathrm{P}<0,01)$ terhadap kadar klorofil enkapsulat pewarna fungsional ekstrak selada laut.

Tabel 3. Nilai rata-rata kadar klorofil enkapsulat pewarna fungsional ekstrak selada laut (ppm).

\begin{tabular}{cc}
$\begin{array}{c}\text { Perbandingan Gelatin (G) dan Maltodekstrin } \\
(\mathbf{M})\end{array}$ & Kadar Klorofil (ppm) \\
\hline GM0 $(1: 0)$ & $19,53 \pm 0,03^{\mathrm{de}}$ \\
GM1 $(1: 1)$ & $19,66 \pm 0,07^{\mathrm{cd}}$ \\
GM2 $(1: 1,5)$ & $19,87 \pm 0,04^{\mathrm{bc}}$ \\
GM3 $(1: 2)$ & $20,61 \pm 0,08^{\mathrm{a}}$ \\
GM4 $(1: 2,5)$ & $20,59 \pm 0,06^{\mathrm{a}}$ \\
GM5 $(1: 3)$ & $20,08 \pm 0,07^{\mathrm{b}}$ \\
GM6 $(1: 3,5)$ & $20,07 \pm 0,07^{\mathrm{b}}$ \\
GM7 $(1: 4)$ & $19,68 \pm 0,04^{\mathrm{cd}}$ \\
GM8 (0:1) & $19,37 \pm 0,04^{\mathrm{e}}$ \\
\hline
\end{tabular}

Keterangan : Huruf yang berbeda di belakang nilai rata-rata menunjukkan perbedaan yang sangat nyata $(\mathrm{P}<0,01)$

Tabel 3 menunjukkan nilai rata-rata kadar klorofil tertinggi diperoleh dari perlakuan GM3 (1:2) sebesar 20,61 ppm dan tidak berbeda dengan GM4 (1:2,5) sebesar 20,59 ppm. Kadar klorofil yang tinggi menandakan proses enkapsulasi terjadi secara maksimal, karena tujuan dari enkapsulasi adalah melindungi bahan inti dari faktor-faktor yang dapat menurunkan kualitas bahan tersebut (Rosemberg et al., 1990). Pada penelitian ini perbandingan gelatin dan maltodekstrin 1:2 dan 1:2,5 mampu melindungi bahan inti dengan maksimal pada enkapsulat ekstrak selada laut. Hal ini disebabkan pada perlakuan GM3 dan GM4 terbentuk emulsi yang paling bagus antara enkapsulan dengan ekstrak sehingga mampu melindungi klorofil paling optimal. Pada perbandingan gelatin dan maltodekstrin yang lebih tinggi mulai dari GM4 mengalami penurunan kadar klorofil karena konsentrasi maltodekstrin yang tinggi mengakibatkan pembentukan emulsi yang kurang bagus.

\section{Kelarutan}

Hasil analisis keragaman menunjukkan bahwa perlakuan perbandingan gelatin dan maltodekstrin berpengaruh sangat nyata $(\mathrm{P}<0,01)$ terhadap kelarutan enkapsulat pewarna fungsional ekstrak selada laut.

Tabel 4 menunjukkan nilai rata-rata kelarutan tertinggi diperoleh dari perlakuan GM8 (Maltodekstrin saja) dengan nilai ratarata $91 \%$. Peningkatan konsentrasi maltodekstrin yang semakin tinggi dapat menyebabkan tingkat kelarutan semakin cepat, karena maltodekstrin mampu meningkatkan total padatan sehingga kadar air menurun. Kelarutan suatu bahan dipengaruhi oleh kadar air bahan tersebut. Bahan dengan kadar air yang tinggi juga memiliki permukaan yang sempit untuk dibasahi karena butiran yang besar sehingga saling melekat diantara butiran tersebut sehingga kelarutannya rendah (Gardjito et al., 2006). Pengukuran kelarutan ini bertujuan agar enkapsulat yang dihasilkan dapat diaplikasikan pada pangan. 
Tabel 4. Nilai rata-rata kelarutan enkapsulat pewarna fungsional ekstrak selada laut $(\%)$.

\section{Perbandingan Gelatin (G) dan Maltodekstrin (M)}

\begin{tabular}{ll}
\hline GM0 $(1: 0)$ & $78 \pm 0,03 \mathrm{e}$ \\
GM1 $(1: 1)$ & $81 \pm 0,02 \mathrm{de}$ \\
GM2 $(1: 1,5)$ & $83 \pm 0,02 \mathrm{~cd}$ \\
GM3 $(1: 2)$ & $83 \pm 0,02 \mathrm{~cd}$ \\
GM4 $(1: 2,5)$ & $80 \pm 0,01^{\mathrm{bcd}}$ \\
GM5 $(1: 3)$ & $84 \pm 0,01^{\mathrm{bc}}$ \\
GM6 $(1: 3,5)$ & $85 \pm 0,01^{\mathrm{bc}}$ \\
GM7 $(1: 4)$ & $86 \pm 0,02^{\mathrm{b}}$ \\
GM8 $(0: 1)$ & $91 \pm 0,01^{\mathrm{a}}$ \\
\hline
\end{tabular}

Keterangan : Huruf yang berbeda di belakang nilai rata-rata menunjukkan perbedaan yang sangat nyata $(\mathrm{P}<0,01)$.

Intensitas Warna $\left(\mathrm{L}^{*}, \mathbf{a}^{*}, \mathrm{~b}^{*}\right)$

Tingkat Kecerahan $\left(L^{*}\right)$

Hasil analisis keragaman menunjukkan bahwa perlakuan perbandingan gelatin dan maltodekstrin berpengaruh sangat nyata $(\mathrm{P}<0,01) \quad$ terhadap tingkat kecerahan enkapsulat pewarna fungsional ekstrak selada laut.

Tabel 5 menunjukkan nilai rata-rata tingkat kecerahan tertinggi diperoleh dari perlakuan GM8 (Maltodekstrin saja) sebesar 46,02 dan tidak berbeda dengan GM7 (1:4) sebesar 45,98. Peningkatan tingkat kecerahan dipengaruhi oleh konsentrasi maltodekstrin yang semakin meningkat di setiap perlakuan. Peningkatan konsentrasi maltodekstrin yang berwarna putih mempengaruhi tingkat kecerahan pada produk enkapsulasi (Purnomo et al., 2014). Semakin tinggi konsentrasi maltodekstrin yang ditambahkan maka semakin tinggi tingkat kecerahan pada produk enkapsulat pewarna fungsional ekstrak selada laut.

Tabel 5. Nilai rata-rata tingkat kecerahan $\left(\mathrm{L}^{*}\right)$.

\begin{tabular}{cc}
\hline $\begin{array}{c}\text { Perbandingan Gelatin (G) dan Maltodekstrin } \\
(\mathbf{M})\end{array}$ & Tingkat kecerahan $\left(\mathbf{L}^{*}\right)$ \\
\hline GM0 (1:0) & $44,86 \pm 0,01^{\mathrm{d}}$ \\
GM1 $(1: 1)$ & $44,95 \pm 0,13^{\mathrm{d}}$ \\
GM2 $(1: 1,5)$ & $44,96 \pm 0,08^{\mathrm{d}}$ \\
GM3 $(1: 2)$ & $45,15 \pm 0,01^{\mathrm{cd}}$ \\
GM4 $(1: 2,5)$ & $45,21 \pm 0,12^{\mathrm{cd}}$ \\
GM5 (1:3) & $45,46 \pm 0,06^{\mathrm{bc}}$ \\
GM6 $(1: 3,5)$ & $45,68 \pm 0,16^{\mathrm{ab}}$ \\
GM7 $(1: 4)$ & $45,98 \pm 0,04^{\mathrm{a}}$ \\
GM8 (0:1) & $46,02 \pm 0,20^{\mathrm{a}}$ \\
\hline
\end{tabular}

Keterangan : Huruf yang berbeda di belakang nilai rata-rata menunjukkan perbedaan yang sangat nyata $(\mathrm{P}<0,01)$.

Tingkat Kemerahan ( $\left.a^{*}\right)$

Hasil analisis keragaman menunjukkan bahwa perlakuan perbandingan gelatin dan maltodekstrin berpengaruh nyata $(\mathrm{P}<0,05)$ 
terhadap tingkat kemerahan $\left(a^{*}\right)$ enkapsulat pewarna fungsional ekstrak selada laut.

Tabel 6 menunjukkan bahwa terjadinya penurunan tingkat kemerahan $\left(a^{*}\right)$ dengan semakin tinggi konsentrasi maltodekstrin. Nilai tingkat kemerahan tertinggi diperoleh dari perlakuan GM0 (1:0) dengan nilai rata- rata 1,71. Konsentrasi maltodekstrin pada produk enkapsulat yang meningkat pada setiap perlakuan yang dapat memudarkan warna merah. Karena maltodekstrin yang berwarna putih dapat mengurangi tingkat kemerahan. (Purnomo et al., 2014).

Tabel 6. Tabel nilai rata-rata tingkat kemerahan $\left(a^{*}\right)$.

\begin{tabular}{cc}
\hline $\begin{array}{c}\text { Perbandingan Gelatin (G) dan Maltodekstrin } \\
(\mathbf{M})\end{array}$ & Tingkat kemerahan $\left(\mathbf{a}^{*}\right)$ \\
\hline GM0 (1: $:)$ & $1,71 \pm 0,01^{\mathrm{a}}$ \\
GM1 $(1: 1)$ & $1,68 \pm 0,01 \mathrm{ab}$ \\
GM2 $(1: 1,5)$ & $1,68 \pm 0,04 \mathrm{ab}$ \\
GM3 (1:2) & $1,68 \pm 0,06 \mathrm{ab}$ \\
GM4 (1:2,5) & $1,68 \pm 0,05 \mathrm{ab}$ \\
GM5 (1:3) & $1,67 \pm 0,03 \mathrm{ab}$ \\
GM6 (1:3,5) & $1,67 \pm 0,04 \mathrm{ab}$ \\
GM7 (1:4) & $1,66 \pm 0,03 \mathrm{ab}$ \\
GM8(0 : 1$)$ & $1,54 \pm 0,02 \mathrm{~b}$ \\
\hline
\end{tabular}

Keterangan : Huruf yang berbeda di belakang nilai rata-rata menunjukkan perbedaan nyata $(\mathrm{P}<0,05)$.

\section{Tingkat Kekuningan (b*)}

Hasil analisis keragaman menunjukkan bahwa perlakuan perbandingan gelatin dan maltodekstrin berpengaruh nyata $(\mathrm{P}<0,05)$ terhadap tingkat kekuningan $\left(b^{*}\right)$ enkapsulat pewarna fungsional ekstrak selada laut.

Tabel 7 menunjukkan bahwa terjadinya penurunan tingkat kekuningan pada setiap perlakuan. Nilai rata-rata tingkat kekuningan tertinggi diperoleh dari perlakuan GM0 (Gelatin saja) dengan nilai rata-rata 16,23. Penurunan tingkat kekuningan dipengaruhi oleh konsentrasi maltodekstrin pada produk enkapsulat pewarna fungsional ekstrak selada laut yang meningkat pada setiap perlakuan. Maltodekstrin yang berwarna putih dapat mengurangi nilai kekuningan (Purnomo et al., 2014).

\section{Uji indeks efektivitas}

Penentuan perlakuan terbaik dalam menghasilkan enkapsulat pewarna fungsional dari selada laut ditentukan berdasarkan metode indeks efektivitas (De Garmo et al., 1984). Hasil perhitungan uji indeks efektivitas dapat dilihat pada Tabel 8 bobot variabel dari hasil kuisioner yang diurutkan menurut prioritas dan kontribusi terhadap hasil produk oleh para ahli dari parameter rendemen, kadar air, kadar klorofil, kelarutan, tingkat kecerahan $\left(\mathrm{L}^{*}\right)$, tingkat kemerahan $\left(a^{*}\right)$, tingkat kekuningan $\left(b^{*}\right)$.

Perlakuan terbaik ditunjukkan dengan jumlah nilai tertinggi. Tabel 8 menunjukkan bahwa perlakuan perbandingan gelatin maltodekstrin GM4 $(1: 2,5)$ mempunyai nilai tertinggi yaitu 0,65 . Hal tersebut menunjukan bahwa perlakuan perbandingan gelatin maltodekstrin GM4 (1:2,5) merupakan perlakuan terbaik yang dapat menghasilkan enkapsulat pewarna fungsional ekstrak selada laut, sehingga dapat digunakan sebagai pewarna alami dalam produk pangan, kosmetik maupun industri. 
Tabel 7. Nilai rata-rata tingkat kekuningan $\left(b^{*}\right)$.

Perbandingan Gelatin (G) dan Maltodekstrin

(M)

\section{Tingkat kekuningan}

(b*)
$16,23 \pm 0,35^{a}$
$14,04 \pm 0,91 \mathrm{ab}$
$13,91 \pm 1,00 \mathrm{ab}$
$13,90 \pm 1,22 \mathrm{ab}$
$13,88 \pm 0,68 \mathrm{ab}$
$13,98 \pm 1,55 \mathrm{ab}$
$13,87 \pm 0,81 a b$
$13,83 \pm 0,58 \mathrm{ab}$
$11,27 \pm 0,17^{\mathrm{b}}$

Keterangan: Huruf yang berbeda di belakang nilai rata-rata menunjukkan perbedaan nyata $(\mathrm{P}<0,05)$.

Tabel 8. Uji indeks evektifitas enkapsulat pewarna fungsional ekstrak selada laut.

\begin{tabular}{|c|c|c|c|c|c|c|c|c|c|}
\hline $\begin{array}{c}\text { Varia } \\
\text { bel }\end{array}$ & & $\begin{array}{c}\text { Rende } \\
\text { men }\end{array}$ & $\begin{array}{c}\text { Kadar } \\
\text { Air }\end{array}$ & $\begin{array}{c}\text { Kada } \\
\text { Kloro } \\
\text { fil }\end{array}$ & $\begin{array}{c}\text { Kelarut } \\
\text { an }\end{array}$ & $\begin{array}{c}\text { Kingkat } \\
\text { Kecera } \\
\text { han (L) }\end{array}$ & $\begin{array}{c}\text { Tingkat } \\
\text { Kemera } \\
\text { han (a) }\end{array}$ & $\begin{array}{c}\text { Tingkat } \\
\text { Kekunin } \\
\text { gan (b) }\end{array}$ & $\begin{array}{c}\text { Jumla } \\
\text { h }\end{array}$ \\
\hline & $\begin{array}{c}\text { BV } \\
\text { ( }\end{array}$ & 2,20 & 2,20 & 4,00 & 2,40 & 1,40 & 1,40 & 1,20 & 14,80 \\
\hline & $\begin{array}{c}\mathrm{BN} \\
\text { ) }\end{array}$ & 0,15 & 0,15 & 0,27 & 0,16 & 0,09 & 0,09 & 0,08 & 1,00 \\
\hline GM0 & $\mathrm{Ne}$ & 0,00 & 1,00 & 0,13 & 0,00 & 1,00 & 1,00 & 1,00 & \\
\hline & $\mathrm{Nh}$ & 0,00 & 0,15 & 0,04 & 0,00 & 0,09 & 0,09 & 0,08 & 0,45 \\
\hline GM1 & $\mathrm{Ne}$ & 0,01 & 0,91 & 0,23 & 0,20 & 0,93 & 0,83 & 0,56 & \\
\hline & $\mathrm{Nh}$ & 0,00 & 0,14 & 0,06 & 0,03 & 0,09 & 0,08 & 0,05 & 0,44 \\
\hline GM2 & $\mathrm{Ne}$ & 0,10 & 0,77 & 0,40 & 0,36 & 0,92 & 0,80 & 0,53 & \\
\hline & $\mathrm{Nh}$ & 0,02 & 0,11 & 0,11 & 0,06 & 0,09 & 0,08 & 0,04 & 0,50 \\
\hline GM3 & $\mathrm{Ne}$ & 0,39 & 0,41 & 1,00 & 0,36 & 0,75 & 0,80 & 0,53 & \\
\hline & $\mathrm{Nh}$ & 0,06 & 0,06 & 0,27 & 0,06 & 0,07 & 0,08 & 0,04 & 0,64 \\
\hline GM4 & $\mathrm{Ne}$ & 0,65 & 0,23 & 0,98 & 0,40 & 0,70 & 0,80 & 0,53 & \\
\hline & $\mathrm{Nh}$ & 0,10 & 0,03 & 0,27 & 0,06 & 0,07 & 0,08 & 0,04 & $\mathbf{0 , 6 5}$ \\
\hline GM5 & $\mathrm{Ne}$ & 0,66 & 0,23 & 0,57 & 0,48 & 0,48 & 0,77 & 0,53 & \\
\hline & $\mathrm{Nh}$ & 0,10 & 0,03 & 0,15 & 0,08 & 0,05 & 0,07 & 0,04 & 0,53 \\
\hline GM6 & $\mathrm{Ne}$ & 0,74 & 0,09 & 0,57 & 0,56 & 0,29 & 0,74 & 0,53 & \\
\hline & $\mathrm{Nh}$ & 0,11 & 0,01 & 0,15 & 0,09 & 0,03 & 0,07 & 0,04 & 0,51 \\
\hline GM7 & $\mathrm{Ne}$ & 1,00 & 0,05 & 0,25 & 0,60 & 0,03 & 0,71 & 0,52 & \\
\hline & $\mathrm{Nh}$ & 0,15 & 0,01 & 0,07 & 0,10 & 0,00 & 0,07 & 0,04 & 0,43 \\
\hline GM8 & $\mathrm{Ne}$ & 0,96 & 0,00 & 0,00 & 1,00 & 0,00 & 0,00 & 0,00 & \\
\hline
\end{tabular}




\section{KESIMPULAN}

\section{Kesimpulan}

Berdasarkan penelitian yang telah dilakukan maka dapat disimpulkan beberapa hal sebagai berikut:

Perlakuan perbandingan gelatin dan maltodekstrin sangat berpengaruh terhadap rendemen, kadar klorofil, kelarutan, tingkat kecerahan $\left(\mathrm{L}^{*}\right)$, berpengaruh terhadap tingkat kemerahan $\left(a^{*}\right)$ dan tingkat kekuningan $\left(b^{*}\right)$ dan tidak berpengaruh terhadap kadar air enkapsulat pewarna fungsional ekstrak selada laut.

Perlakuan terbaik untuk menghasilkan enkapsulat pewarna fungsional ekstrak selada laut adalah perbandingan gelatin dan maltodekstrin 1:2,5 dengan karakteristik rendemen $10,38 \%$, kadar air $8,61 \%$, kadar klorofil total 20,59 , kelarutan $80 \%$, tingkat kecerahan $\left(\mathrm{L}^{*}\right) 45,21$, tingkat kemerahan $\left(\mathrm{a}^{*}\right)$ 1,68 dan tingkat kekuningan $\left(b^{*}\right)$ 13,88.

\section{Saran}

Berdasarkan hasil penelitian ini dapat disarankan agar dilakukan penelitian lebih lanjut mengenai penggunaan enkapsulan yang lain serta penambahan konsentrasi emulsifier untuk meningkatkan nilai efisiensi enkapsulasi dan perbandingan jenis pelarut untuk mendapatkan polaritas yang tepat untuk mengestrak klorofil.

\section{DAFTAR PUSTAKA}

AOAC, 1999. Official Methods of Analysis (15th Ed.) K. Helrich (Ed.). Virginia.

Caliskan, G., and S. N. Dirim. 2016. The Effect of Different Drying Processes and the Amounts of Maltodextrin Addition on the Powder Properties of Sumac Extract Powders, Journal of Powder Technology, 287, 308-314.
De Garmo, E.P., Sullivan W.G and C.R. Canada. 1984. Engineering Economy. $7^{\text {th }}$ Edition. Mac. Millan Publ Co. New York.

Dewi, N. N. D. T., L. P. Wrasiati., dan G. P. Ganda-Putra. 2016. Pengaruh konsentrasi pelarut etanol dan suhu maserasi terhadap rendemen dan kadar krorofil produk enkapsulasi selada laut (Ulva lactuca). Jurnal Rekayasa dan Manajemen Agroindustri 4 (3) : 1-4.

Endang, S., dan Prasetyastuti. 2010. Pengaruh pemberian juice lidah buaya (aloe vera 1.) terhadap kadar lipid peroksida (mda) pada tikus putih jantan hiperlipidemia. Jurnal Farmasi Kedokteran 3 (1) : 353-362.

Ernawati, U. R., L. U. Khasanah., dan R.B.K Anandito. 2014. Pengaruh variasi nilai dextrose equivalen (De) maltodekstrin terhadap karakteristik mikroenkapsulan pewarna alami daun jati (Tectona grandis l.f.). Jurnal Teknologi Pertanian 2 (15) : 111-120.

Gardjito, M., A. Murdiati., dan N. Aini. 2006. Mikroenkapsulasi $\beta$-karoten buah labu kuning dengan enkapsulan whey dan karbohidrat. Jurnal Teknologi Pertanian. 2 (1) : 13-18.

Hui, Y. 2006. Handbook of Food Science Technology and Enginering Volume I. CRC Press, USA.

Hustiany, R. 2006. Modifikasi asilasi dan Suksunilasi Pati Tapioka sebagai Bahan Enkapsulasi Komponen Flavor. Disertasi. Tidak dipublikasikan. Pasca Sarjana. Institut Pertanian Bogor, Bogor.

Julyasih,K.S.M., I.G.P.Wirawan., W.S. Harijani., dan W. Widajati. 2009. Aktivitas Antioksidan Beberapa Jenis Rumput Laut (Seaweeds) Komersial Di Bali. Seminar Nasional "Akselerasi Pengembangan Teknologi Pertanian Dalam Mendukung Revitalisasi 
Pertanian'. Fak. Pertanian dan LPPMUPN "Veteran"Jawa Timur.

Nollet, LML. 2004. Handbook of Food Analysis Physical Characterzati- ion and Nutrient Analysis. Marcel Dekker Incorporation, New York.

Palupi, N. W., L. U. Khasanah., dan R. B. K. Anindito. 2014. Pengaruh ratiao kombinasi maltodekstrin, karagenan dan whey terhadap karakteristik mikroenkapsulan pewarna alami daun jati (Tectona grandis L. f.). Jurnal Aplikasi Teknologi Pangan 3 (3) : 121-129.

Purnomo, W., L. U. Khasanah., dan R. B. K. Anindito. 2014. Pengaruh ratio kombinasi maltodekstrin, karagenan dan whey terhadap karakteristik mikroenkapsulan pewarna alami daun jati (Tectona grandis L. f.). Jurnal Aplikasi Teknologi Pangan 2 (3) : 121-129.

Rosemberg M., I. J. Kompolmen., and Y. Talmon. 1990. Factor affecting retention in spraydriying microencapsulation of volatile materials. J Agric Food Chem 38 :1288-94.
Silalahi, S. E., L. P. Wrasiati., dan A. A. M. D. Anggreni. 2014. Karakteristik bubuk ekstrak kulit buah jeruk mandarin (Citrusreticulala) pada perlakuan lama maserasi dan konsentrasi maltodekstrin. Jurnal Rekayasa dan Manajemen Agroindustri, 3(1) : 1-4.

Sudarmadji, S., Surhadi., dan B. Haryono. 1989. Analisa Bahan Makanan dan Pertanian. Penerbit Liberty, Yogyakarta.

Weaver, C. 1996. The Food Chemistry Laboratory. CRC Press, Boca Raton, New York, London, Tokyo.

Xiao-ling, L., C. Rong, and Y. Zai-yong. 2003. Elementary study on nutritional compositions of the green alga, Ulva lactuca in the South China SeaJournal of Natural Science 6 (2) : 79-83.

Yuliani,S., Desmarwarni., dan N. Harimurti.2007. Pengaruh Laju Alir Umpan dan Suhu Inlet Spray Drying Pada Karakteristik Mikroenkapsul Oleoresin Jahe. J.Pascapanen 4 (1) : 18-26. 